\title{
The Impact of Tourist Feedback in the Virtual Community on the Purchase Intention
}

\author{
Ionica Oncioiu $^{1}$ \\ ${ }^{1}$ Dimitrie Cantemir Christian University, Romania \\ Correspondence: Ionica Oncioiu, Dimitrie Cantemir Christian University, 5A Brizei Street, Constanta, Romania. \\ Tel: 40-241-682-238. E-mail: nelly_oncioiu@yahoo.com
}

Received: January 17, 2014

Accepted: January 30, 2014

Online Published: February 24, 2014

doi:10.5539/ibr.v7n3p28

URL: http://dx.doi.org/10.5539/ibr.v7n3p28

\begin{abstract}
Today, the Internet provides human beings with a new way of communication, which is more efficient and effective. This study investigates how the message content and involvement in an online forum influenced the tourism consumers' purchase intention and conducted online experiments involving 534 subjects. According to the research results, negative messages have stronger effects than positive messages, which may lead to stronger disasters on e-Small and medium tourism enterprise or tourism products. This finding offers potential for finding better ways for sellers (travel agencies) or managers of Small and medium-sized tourism enterprises in a virtual community. Finally, the results of this study also demonstrated positive relationship between the tourism consumers' online feedback and their purchase decision. The conclusion presents implications, limitations, and directions for future research.
\end{abstract}

Keywords: virtual community, tourism consumers, web consumer, purchase intention

\section{Introducation}

In the "Digital Economy", due to the technology development and diffusion, tourism products are becoming relatively similar based on their specifications and therefore, brands started to conduct different strategies in order to differentiate themselves in the marketplace. Small and medium-sized tourism enterprises and travel agencies can substantially improve their market position and increase turnovers and margins if they give the customer orientation a top priority and pursue this goal systematically and methodically. To achieve the goals mentioned above, it is indispensable to gain sound knowledge on tourism customers and their needs, and to analyze both of them in order to stay profitable and competitive in the long run.

However, tourism businesses should use digital distribution channels for their product to come into contact with virtual consumers, which means that social-media-platforms should allow consumers to interact and inform each other and personal digital assistants should help people stay connected while away from home or office. In other words, a weblog is a personal writing space, its public nature suggesting a need to communicate, (Efimova \& Hendrick, 2005) and inviting feedback. At the same time, Kelleher and Miller (2006) put emphasis on the relevance of the organizational blogs which seem to appear at the intersection of personal reflection and professional communication. Using social networks, feedback messages spread like viruses being forwarded from one participant-friend or follower - to another, which is why this form of advertising is also called e-marketing. The market leader Facebook has a worldwide membership of more than 1 billion active users (Facebook, 2012).

However, according to Fujimoto (2012) due to the prevalence of social-media-platforms, this type of analysis has not only extended to the tourism consumers' opinions for gathering unbiased product information, but has also provided the opportunity for tourism consumers to offer their own purchase experience by engaging in electronic word of mouth. Furthermore, tourism consumers' feedback can be leveraged for organizational consumption with respect to new product development, product features and consumer expectations. The buy-side e-commerce transactions with suppliers and the sell-side e-commerce transactions with customers can also be considered to be key business processes (Srinivasan, Anderson, \& Ponnavolu, 2002). A social network and feedback messages play an important role in this respect. In order to do so, in this paper we examine the effect of brand attitude, brand experience and self-congruity on recipients' forwarding behavior on the basis of a real feedback campaign information regarding Romanian agro-tourism destination from tourism consumers on 
Facebook.

This study discusses, based on Cheung's (2009) congruity theory and Nienstedt, Huber and Seelmann (2012), a model about how the message's regarding Romanian agrotourism destination, involvement in an online forum influenced the tourism consumer purchase intention and combined independent variables which include the message numbers and the message content, with moderating variables which include involvement and dependent variables - purchase intention, and chose ten questions to measure the tourism consumer's involvement. Based on the results of this analysis, we can affirm that the message number and positive messages in virtual community can influence tourism consumer purchase intention.

\section{Theoretical and Empirical Studies}

A review of economics literature indicates the problem of tourism consumer influence on the purchase intention as an insufficiently explored topic.

Most studies are based on Hovlands' (1948) four factors of interpersonal communication: (1) the communicator who transmits the communication, (2) the stimulus concerning the message content and container, (3) the recipient who responds to the communication and (4) the responses made to the communication by the communicate. However, Grewal (1998) presented that consumers' online comments would influence the consumer's perceived value and he indicated that there is a positive relationship among consumers' perceived value and the purchase intention. Also Holland and Baker (2001) consider many virtual applications such as online communities and blogs can help provide interactivity to consumers. Thus, social-media-platforms on the Internet influence the information receivers more quickly, broadly, widely, significantly and without any geographic limitation (Gelb \& Sundaram, 2002).

In 1948, Lazarsfeld mentioned in their study the "two-step-flow-model of communication" and they concluded that ultimately, interpersonal communication is the most influential on people's behavior. Maheswaran and Meyers-Levy (1990) pointed that there is a stronger impact on encouraging preventive behaviour with positive content than with a negative one, and those remarks have an influence on a consumer's purchase intention. Cheng and $\mathrm{Wu}$ (2010) have pointed the appropriateness of using different communication strategies for low and high involvement consumers. This means that, in the information era, the virtual communities' communication has as a crucial influence role on consumer behaviour, including the tourism consumer's purchase intention.

Besides, increasingly more often, the travel agencies or managers of Small and medium-sized tourism enterprises achieved that social-media-platform communities will become the most competitive tourism e-business activities on the Internet. The influence the tourism consumer feedback number on the purchase intention could help the suppliers of tourism products to consider the effect regarding the brand attitude. Thus, the most important element in evaluating a tourism consumer's purchase intention and its resulting behavior is attitude.

According to Singh, Kumar and Singh (2010), the engagement theory comprises the dimensions of the 4I (Involvement, Interaction, Intimacy and Influence). As the organization increases the contact with the consumer by increasing its own efforts, the chances of forming a relationship with the consumer also increases proportionally. In this study, we focus on the level of user engagement achieved by the interaction between Romanian agrotourism destinations and consumer which is an important contributing factor to the purchase intention tourism product. This empirical research thus focused on the behaviour of virtual communities' members regarding Romanian agrotourism destination on the basis of their viewpoints.

Based on this statement, we propose the following hypotheses:

H1: The more feedback the tourism consumer gives, the greater influence it has the influence consumers' purchase intention in an online forum.

H2: The more feedback the tourism consumer gives, the more positive influence there is on the consumers' purchase intention.

H3: The more negative feedback the tourism consumer gives, the more negative influence there is on the consumers' purchase intention.

H4: The negative feedback of tourism consumers, compared to the positive one has stronger effect on consumers' purchase intention in an online forum.

Furthermore, the given overview of prior research indicates a strong relationship between the recipients' beliefs and attitudes of tourism consumer and the actual forwarding process of the consumers' purchase intention in an online forum. 


\section{Methodology Research}

This experiment is designed specifically to examine the relationship between the effects of feedback tourism consumer messages regarding Romanian agro tourism destinations and the purchase intention. The subjects are tourists who visited Romanian agro tourism destinations, and who also have online forum experiences. For the final survey, a total of 534 survey questionnaires were collected. We approached an online survey running from 10/01/2013 until 11/30/2013 in which participants were invited to participate via Facebook. Thus, the receivers of the survey knew about it and belonged to a relevant target group.

We are following the basic attributes of the respondents, including major items in this study: gender, age, education, occupation. The sample included consumers from a variety of backgrounds: $56.42 \%$ of respondents are female and $43.58 \%$ male; more than $41.28 \%$ of the respondents are $21-30$ years old and $58.72 \%$ of the respondents are $31-65$ years old.

\section{Results}

This study makes the number of tourism consumers who give feedback an independent variable and the purchase intention as a dependent variable. Data was analysed using ANOVA with participants overall shift to inspect H1.

Table 1 shows the results of the ANOVA. It is shown that there are significant differences between the tourism consumer number and the purchase intention $(\mathrm{p}<0.001)$. The results support our predictions of H1.

Table 1. Effects of feedback tourism consumer message number on purchase intention

\begin{tabular}{llllll}
\hline & SS & DF & MS & F-Value & P-value \\
\hline Between & 5.676 & 0.75 & 5.676 & $15.406^{* * *}$ & 0.000 \\
Within & 74.890 & 203.25 & 0.276 & & \\
Sum & 80.566 & 204 & & & \\
\hline
\end{tabular}

Notes: $* \mathrm{p}<0.05, * * \mathrm{p}<0.01, * * * \mathrm{p}<0.001$.

On the other hand, this study makes the "positive feedback" tourism consumers an independent variable and the purchase intention a dependent variable. This data was analysed using one-way ANOVA with participants overall shift to inspect H3, the result being shown in Table 2. It's stated that there are significant differences between the tourism consumer number and the purchase intention $(\mathrm{p}<0.001)$, and a further analysis of the main value of the purchase intention. The main value of the purchase intention increased from 2.98 to 3.18 when the number of "positive feedback" tourism consumers message increased from 1.5 to 6 . The results supported our predictions of $\mathrm{H} 2$.

Table 2. Effects of positive feedback tourism consumer on the purchase intention

\begin{tabular}{llllll}
\hline & SS & DF & MS & F-Value & P-value \\
\hline Between & 1.929 & 1 & 1.929 & $5.24^{*}$ & 0.006 \\
Within & 36.295 & 102 & 0.267 & 20.25 & \\
Sum & 38.224 & 103 & & & \\
\hline
\end{tabular}

Notes: $* \mathrm{p}<0.05, * * \mathrm{p}<0.01, * * * \mathrm{p}<0.001$.

This study also makes the "negative feedback" tourism consumer an independent variable and the purchase intention a dependent variable. This data was analysed using one-way ANOVA with participants overall shift to inspect H3. The results shown in Table 3 indicate that there are significant differences between the "negative feedback" tourism consumer number and the purchase intention $(p<0.001)$. The main value of the purchase intention decreased from 3.104 to 2.445 when the number of "negative feedback" tourism consumers increased from 1.5 to 6 . The results support our predictions of $\mathrm{H} 3$. 
Table 3. Effects of negative feedback tourism consumer message number on purchase intention

\begin{tabular}{llllll}
\hline & SS & DF & MS & F-Value & P-value \\
\hline Between & 25.678 & 1 & 25.678 & $68.887^{* *}$ & 0.000 \\
Within & 37.462 & 104 & 0.351 & & \\
Sum & 63.140 & 105 & & & \\
\hline
\end{tabular}

Notes: ${ }^{*} \mathrm{p}<0.05, * * \mathrm{p}<0.01, * * * \mathrm{p}<0.001$.

This data will put the moderating variable - “tourism customers' involvement", the being analysed using one-way ANOVA with participants overall shift to inspect the influence of tourism customers' involvement in feedback message number on the purchase intention. It is shown in Table 4 that there are significant differences between the "negative feedback" tourism consumer number and the purchase intention $(p<0.05)$, and that the main value of the purchase intention. The main value of purchase intention in low tourism customers' involvement (5.01) is higher than the high tourism customers' involvement (4.925). Finally, the results support our predictions of the higher involvement and validate that the lower influence of the tourism consumers' feedback on the purchase decision is in an online forum.

Table 4. The interaction effect of involvement and feedback tourism consumer message number on purchase intention

\begin{tabular}{|c|c|c|c|c|c|}
\hline Sources & Type III SS & FD & MS & F-Value & P-Value \\
\hline Corrected Model & 19.2681 & 4 & 6.4228 & $11.1588 * * *$ & 0.000 \\
\hline Intercept & 5314.7510 & 1 & 5314.7510 & $9233.7299 * * *$ & 0.000 \\
\hline Message Number & 12.1049 & 1 & 12.1049 & $21.0306 * * *$ & 0.0013 \\
\hline Involvement & 0.1383 & 1 & 0.1383 & 0.2401 & 0.8275 \\
\hline Involvement * Message Number & 6.5592 & 1 & 6.5592 & $11.3958 * *$ & 0.0038 \\
\hline Error & 194.2583 & 338 & 0.7195 & & \\
\hline Total & 5623.7500 & 343 & & & \\
\hline Corrected Total & 213.5265 & 341 & & & \\
\hline
\end{tabular}

Note: $* \mathrm{p}<0.05, * * \mathrm{p}<0.01, * * * \mathrm{p}<0.001$.

\section{Conclusions and Suggestions}

The major objective of this study is to investigate the interrelationships among the effects of the tourism consumers' feedback message and its content. Based on the results of this study, several conclusions could be drawn. Firstly, the more tourism consumer messages will attract others' awareness. Secondly, its content has an influence on the purchase intention. The more tourism consumers' feedback there is, the more positive influence it has on tourism consumers' purchase intention, and more negative feedback leads to a more negative influence on tourism consumers' purchase intention. In addition, negative feedback compared to the positive one has stronger effects on tourism consumers' purchase intention in online forum.

This study has implications for travel agencies or managers of Small and medium-sized tourism enterprises. Firstly, more positive feedback will increase sales. According to the results of this study, the tourism consumer feedback its content certainly have an influence on the purchase intention in an online forum. In addition, when tourism consumers see more online like messages, they may share the tourism product information or their own experiences and thus go on positively influencing other potential tourism consumers. Secondly, sellers should manage the negative feedback efficiently. According to the results research, the negative feedback messages have stronger effects than the positive ones, which may lead to stronger disasters on the tourism enterprise or tourism products. According to the results of this study, customer involvement has a moderating effect on the feedback message which influences the purchase intention.

Like most empirical research, this study is not without limitations. Firstly, the survey sample was limited only to 
participants of the online Facebook and thus is not representative for all internet users. Secondly, further research should extend the current framework and integrate more variables concerning the effects of travel agencies or Small and medium-sized tourism enterprises related to stimuli and attitudes. Therefore, it is difficult to generalize the results.

\section{References}

Bansal, H. S., \& Voyer, A. P., (2000). Word-of-Mouth Processes within a Services Purchase Decision Context. Journal of Service Research, 3(2), 166-177. http://dx.doi.org/10.1177/109467050032005

Bian, X., \& Moutinho, L. (2011). The role of brand image, product involvement, and knowledge in explaining consumer purchase behaviour of counterfeits direct and indirect effects. European Journal of Marketing, 45(1/2), 191-216. http://dx.doi.org/10.1108/03090561111095658

Cheng, F. F., \& Wu, C. S. (2010). Debiasing the framing effect: The effect of warning and involvement. Decision Support Systems, 49(3), 328-334.

Cheung, M., Luo, C., Sia, C., \& Chen, H. (2009). Credibility of Electronic Word-of-Mouth: Informational and Normative Determinants of Online Consumer Recommendations. International Journal of Electronic Commerce, 13(4), 9-38. http://dx.doi.org/10.2753/JEC1086-4415130402

Della Bitta, A. J., Monroe, K. B., \& McGinnis, J. M. (1981). Consumer perceptions of comparative price advertisements. Journal of Marketing Research, 18(4), 416-427. http://dx.doi.org/10.2307/3151334

Doh, S. J., \& Hwang, J. S. (2009). How Consumers Evaluate eWOM (Electronic Word-of-Mouth) Messages. Cyberpsychology and Behavior, 12(2), 193-197. http://dx.doi.org/10.1089/cpb.2008.0109

Efimova, L., \& Hendrick, S. (2005). In search for a virtual settlement: An exploration of weblog community boundaries. In Communities \& Technologies (Vol. 5). Retrieved from https://doc.novay.nl/dsweb/Get/Document-46041/weblog -community-boundaries.pdf

Facebook. (2012). Facebook Statisticsheet. Retrieved February 23, 2013, from http://www.facebook.com/press/info. php?statistics

Fujimoto, K. (2012). Computational approach to prediction of attitude change through eWOM messages involving subjective rank expressions. Journal of Emerging Technologies in Web Intelligence, 4(1), 15-25. http://dx.doi.org/10.4304/jetwi.4.1.15-25

Gelb, B. D., \& Sundaram, S. (2002). Adapting to "word of mouse". Business Horizons, 45(4), $21-25$. http://dx.doi.org/10.1016/S0007-6813(02)00222-7

Goldsmith, R. E., Flynn, L. R., Goldsmith, E., \& Stacey, E. C. (2010). Consumer attitudes and loyalty towards private brands. International Journal of Consumer Studies, 34(3), 339-348. http://dx.doi.org/10.1111/j.1470-6431.2009.00863.x

Grewal, D., Kent, B. Monroe, K. B., \& Krishnan, R. (1998). The effects of price-comparison advertising on buyers' perceptions of acquisition value, transaction value, and behavioral intentions. The Journal of Marketing, 62(2), 46-59.

Holland, J., \& Baker, S. M. (2001). Customer participation in creating site brand loyalty. Journal of Interactive Marketing, 15(4), 34-45. http://dx.doi.org/10.1002/dir.1021

Hovland, C. I. (1948). Social Communication. Proceedings of the American Philosophical Society, 92(5), 371-375.Retrieved from http://www.jstor.org/stable/3143048

Hsiao, K. L., Lu, H. P., \& Lan, W. C. (2013). The influence of the components of storytelling blogs on readers' travel intentions. Internet Research, 23(2), 160-182. http://dx.doi.org/10.1108/10662241311313303

Hsu, C. L., Lin, J. C. C., \& Chiang, H. S. (2013). The effects of blogger recommendations on customers' online shopping intentions. Internet Research, 23(1), 69-88. http://dx.doi.org/10.1108/10662241311295782

Jiang, P., \& Rosenbloom, B. (2005). Customer intention to return online: price perception, attriute-level performance, and satisfaction unfolding over time. European Journal of Marketing, 39(1/2), 150-174. http://dx.doi.org/10.1108/03090560510572061

Kelleher, T., \& Miller, B. M. (2006). Further evidence on the consumer involvement profile: five antecedents of involvement. Psychology and Marketing, 10(4), 347-355.

Lazarsfeld, P. F., Berelson, B., \& Gaudet, H. (1948). The people's choice: How the voter makes up his mind in a presidential campaign (2nd ed.). New York: Columbia University. 
Maheswaran, D., \& Meyers-Levy, J. (1990). The influence of message framing and issue involvement. Journal of Marketing Research, 27(3), 361-367. http://dx.doi.org/10.2307/3172593

Nienstedt, H.-W., Huber, F., \& Seelmann, C. (2012). The impact of the congruence between the brand personality and the self perception of the consumer on the loyalty to print and online issues of magazine brands. The International Journal of Media Management, 14(1), 3-26. http://dx.doi.org/10.1080/14241277.2011.602033

Rothaermel, F. T., \& Sugiyama, S. (2001). Virtual Internet communities and commercial success: Individual and community-level theory grounded in the atypical case of Time Zone.com. Journal of Management, 27(3), 297-312. http://dx.doi.org/10.1177/014920630102700305

Schultz, D. (2000). Customer/Brand Loyalty in an Interactive Marketplace. Journal of Advertising Research, 40(3), 41-53. Retrieved from $\mathrm{http}: / / \mathrm{www}$.journalofadvertisingresearch.com/ArticleCenter/default.asp?ID=49269\&Type= Article

Sher, P., \& Lee, S. (2009). Consumer Skepticism and Online Reviews: An Elaboration Likelihood Model Perspective. Social Behavior and Personality: An international Journal, 37(1), 137-144. Retrieved from http://www.sbp-journal.com/index.php/sbp/article/view/1817

Singh, A., Kumar, B., \& Singh, V. K. (2010). Customer Engagement: New Key Metric of Marketing. International Journal of Art and Sciences, 3(13), 347-356.

Srinivasan, S. S., Anderson, R., \& Ponnavolu, K. (2002). Customer loyalty in e-commerce: an exploration of its antecedents and consequences. Journal of retailing, 78(1), 41-50. http://dx.doi.org/10.1016/S0022-4359(01)00065-3

Wu, C. H., Kao, S. C., \& Lin, H. H. (2013). Acceptance of enterprise blog for service industry. Internet Research, 23(3), 260-297. http://dx.doi.org/10.1108/10662241311331736

Zaichkowsky, J. L. (1985). Measuring the involvement construct. Journal of Consumer Research, 12(3), 341-352. http://dx.doi.org/10.1086/208520

\section{Copyrights}

Copyright for this article is retained by the author(s), with first publication rights granted to the journal.

This is an open-access article distributed under the terms and conditions of the Creative Commons Attribution license (http://creativecommons.org/licenses/by/3.0/). 